\title{
PENGARUH LATIHAN SENAM SEHAT INDONESIA TERHADAP PENINGKATAN KAPASITAS PARU-PARU BAGI LANSIA DI UNIVERSITAS MAJALENGKA
}

\author{
Indrayogi, Maya Nurhayati \\ Universitas Majalengka, Indonesia \\ indrayogi13@gmail.com
}

\begin{abstract}
In developing of elderly in Higher Education, there are no activities to maintain physical condition. Through sports activities that are very potential to be carried out because of many elderly people in Universitas Majalengka. Besides doing physical activities in the form of exercises that can meet the oxygen requirements needed at work or exercise time, it is expected to be able to maintain and improve physical condition, because oxygen cannot be stored as supplies in the body, what can be done is to maintain and improve the ability of organs of the body that function to absorb and distribute oxygen so that it is always in good condition. This research method is a quasi-experimental method with the type of pre-test and the post-test group without control design. The population in the amount of 20 elderly people at Universitas Majalengka. The instrument used in this study was a modified Spirometer. This tool is used to measure lung vital capacity. Based on the results of the study it can be concluded that Senam Sehat Indonesia can affect and contribute significantly to the improvement of the vital lung capacity of the elderly.
\end{abstract}

Keywords: Lung Vital Capacity; Elderly; Senam Sehat Indonesia

\section{ABSTRAK}

Dalam pembinaan usia lanjut di Perguruan Tinggi belum ada kegiatan untuk memelihara kondisi fisik. Melalui kegiatan olahraga yang sebenarnya sangat berpotensi untuk dilaksanakan karena banyak lansia di lingkungan Universitas Majalengka. Selain itu dengan melakukan aktifitas fisik berupa latihan yang dapat mencukupi kebutuhan oksigen yang diperlukan pada waktu kerja atau latihan maka diharapkan dapat memelihara dan meningkatkan kesegaran jasmani, karena oksigen tidak dapat di simpan sebagai persediaan dalam tubuh maka yang dapat dilakukan adalah menjaga dan meningkatkan kemampuan organ-organ tubuh yang berfungsi menyerap dan menyalurkan oksigen agar selalu dalam kondisi baik. Metode penelitian ini adalah metode quasi eksperiment dengan jenis pre-test and post-test group without control design. Populasi dalam berjumlah 20 orang lansia yang ada di Universitas Majalengka, semua populasi dijadikan sampel. Instrument yang digunakan dalam penelitian ini adalah Spirometer yang dimodifkasi. Alat ini digunakan untuk melakukan pengukuran kapasitas vital paru. Berdasarkan hasil penelitian dapat diambil kesimpulan bahwa Senam Sehat Indonesia dapat mempengaruhi dan memberikan kontribusi yang signifikan terhadap peningkatan kapasitas vital paru usia lanjut.

Kata Kunci: kapasitas vital paru; usia lanjut; senam sehat indonesia

Submitted Sep 28, 2020 | Revised Nov 06, 2020 | Accepted Nov 11, 2020

\section{Pendahuluan}

Pendidikan keterampilan hidup sehat pada dasarnya merupakan penanaman kebiasaan yang meliputi kesehatan fisik berupa tingkat kesegaran jasmani, kesehatan mental dan sosial. Adanya motto "Mens sana in corpore sano" yang merupakan semboyan hidup Bangsa Romawi terkesan bahwa tubuh yang sehat itu dianggap sebagai suatu presupposisi atau Condisi Sine Quanom, yang berupa "manusia sempurna", terkait dua unsur bahwa dalam badan yang sehat terdapat jiwa yang sehat pula. (Indrayogi, 2020)

Physical activity is considered as one out of the ten leading health indicators of the public health.The physical and mental health benefits of physical activity, such as reducing the risk of developing heart disease, diabetes, colon cancer, high blood pressure, breast cancer, low back pain and depression. (U.S. Department of Health and Human Services, 2000) dalam Cheung, Siu Yin 
(International Journal of Physical Education, Sports and Health 2020;7 (4): 11-15). Maksud dari pernyataan tersebut yaitu Aktivitas fisik dianggap sebagai salah satu dari sepuluh indikator kesehatan utama kesehatan masyarakat. Manfaat kesehatan fisik dan mental dari aktivitas fisik, seperti mengurangi risiko penyakit jantung, diabetes, kanker usus besar, tekanan darah tinggi, kanker payudara, nyeri pinggang dan depresi.

Inadequate physical activity and a sedentary lifestyle are important causes of many of the major diseases of developed societies, including coronary artery disease, stroke, hypertension, diabetes, obesity, osteoporosis, and arthritis. There has been an explosion of information over the past two decades on the health benefits of exercise. In addition, exercise and nutrition are closely linked, with each modifying the effects of the other. (Oluwasegun, 2018). Maksudnya yaitu aktivitas fisik yang tidak memadai dan gaya hidup yang tidak aktif adalah penyebab penting dari banyak penyakit utama masyarakat maju, termasuk penyakit arteri koroner, stroke, hipertensi, diabetes, obesitas, osteoporosis, dan radang sendi. Telah banyak informasi selama dua dekade terakhir tentang manfaat kesehatan dari olahraga. Selain itu, olahraga dan nutrisi sangat erat kaitannya, dengan masing-masing memodifikasi efek yang lain.

Good fitness is the main asset for someone to do physical activities repeatedly in a relatively long time. It does not cause significant fatigue. Physical fitness is the body's ability to do physical work that is done every day without causing significant fatigue. Kebugaran yang baik adalah aset utama seseorang untuk melakukan aktivitas fisik berulang kali secara relative lama. Itu tidak menyebabkan kelelahan yang signifikan. Kebugaran fisik adalah kemampuan tubuh untuk melakukan pekerjaan fisik yang dilakukan setiap hari tanpa sebab kelelahan yang signifikan, (Oktariyana, Asmawi, \& Zamzami, 2020).

Menurut Kinsella dan Taeuber dalam Darmojo dan Martono (2004), peningkatan jumlah orang usia lanjut yang di Indonesia diperkirakan antara tahun 1990-2025 sebesar $414 \%$ Kondisi ini akan menempatkan Indonesia pada urutan ke-3 yang memiliki populasi usia lanjut terbanyak di dunia pada tahun 2022, setelah Cina dan India. Hal ini dapat menimbulkan masalah sosial khususnya menyangkut masalah kesehatan dan kesejahteraan hidup warga usia lanjut apabila tidak ditangani dengan baik. Jumlah penduduk lanjut usia (lansia) di Indonesia terus bertambah. Hingga 2019 ini, lansia sudah mencapai 7 persen dari total penduduk. Angka ini diperkirakan akan bertambah hingga 9,9 persen atau 27 juta jiwa (Nibras, 2019).

Penting untuk diperhatikan pada lansia ialah komposisi tubuh (persentase lemak tubuh). Pertambahan usia biasanya disertai dengan perubahan komposisi tubuh, penurunan fungsi organ dan metabolisme, Pada kelompok lansia umumnya terdapat kecenderungan penurunan aktifitas fisik sehingga terjadinya ketidakseimbangan yang mengakibatkan banyak permasalahan serta menimbulkan berbagai masalah kesehatan pada lansia (Beltasar dan Novi, 2010).

The reviewed studies suggest that although motor performance tends to decline in old age, learning capabilities remain intact, and older adults are able to achieve considerable performance gains. The extent to which the learning capability varies with age, however, has to be considered very carefully. While most studies revealed that performance gains in fine motor tasks are diminished in older adults, results for gross-motor-skill learning are more contradictory. Additionally, there is considerable agreement on the finding that age-related learning differences are statistically more robust in complex tasks, whereas in low-complexity tasks, the learning of younger and older adults is very similar. This applies to fine and gross motor skills. Relative age differences seem to become enlarged when effortful resources are required for motor performance. Thus, the decline in motor learning that accompanies aging is task specific and not absolute. (Claudia Voelcker-Rehage, 2008)

Dalam program pembinaan usia lanjut di Perguruan Tinggi belum ada kegiatan untuk meningkatkan kondisi fisik. Melalui kegiatan olahraga yang sebenarnya sangat berpotensi untuk dilaksanakan karena banyak lansia di lingkungan Universitas Majalengka. Selain itu dengan melakukan aktifitas fisik berupa latihan yang dapat mencukupi kebutuhan oksigen yang diperlukan pada waktu 
kerja atau latihan maka diharapkan dapat memelihara dan meningkatkan kesegaran jasmani, karena oksigen tidak dapat di simpan sebagai persediaan dalam tubuh maka yang dapat dilakukan adalah menjaga dan meningkat kemampuan organ-organ tubuh yang berfungsi menyerap dan menyalurkan oksigen agar selalu dalam kondisi baik. Latihan fisik ini sifatnya aerobik, dalam hal ini salah satu latihan yang cocok untuk usia lanjut adalah Senam Waitankung atau di Indonesia dikenal dengan nama Senam Sehat Indonesia. (BKKBN, 1996).

Senam Sehat Indonesia adalah senam yang memanfaatkan oksigen melalui pernafasan untuk dioksidasi dalam tubuh untuk mencapai kesehatan jasmani dan rokhani. Dilihat dari lamanya latihan, Senam Sehat Indonesia termasuk latihan aerobik yaitu lama latihan lebih dari 12 menit. Senam Sehat Indonesia dilihat dari kaca mata olahraga mengandung unsur latihan peregangan, latihan meningkatkan kelenturan sendi, latihan balance dan koordinasi yang bermanfaat untuk menguatkan fungsi sistem lokomotor, yaitu sendi tulang, otot dan saraf tepi. Selain itu juga meningkatkan ketahanan jantung dan paru-paru, namun tidak meningkatkan daya ledak otot, kecepatan dan ketangkasan. (Baranas SSI, 1989).

\section{Metode Penelitian}

Metode penelitian yaitu dengan menggunakan metode quasi eksperiment dengan jenis pre-test and post-test group without control design.Populasi dalam penelitian ini adalah semua usia lanjut di Universitas Majalengka yang berjumlah 20 orang. Teknik pengambilan sampel dalam penelitian ini adalah Total Sampling, jadi semua populasi dijadikan sampel yaitu berjumlah 20 orang. Metode pengumpulan data dalam penelitian ini adalah dengan jenis pre-test and post-test group design yang terdiri dari pre- test, treatment dan post-test.

Tujuan diadakan pre-test adalah untuk mendapatkan data test yang berupa pengukuran Kapasitas Vital Paru usia lanjut sebelum diadakan treatment. Treatment. Latihan Senam Sehat Indonesia dilakukan sebanyak 16 kali pertemuan ditambah 2 kali pertemuan untuk pre-test dan posttest. Frekuensi pertemuan 3 kali setiap minggu. Post-test. Tujuan post-test adalah untuk mendapatkan data kapasitas vital paru usia lanjut setelah melakukan Senam Sehat Indonesia.

Analisis data menggunakan rumus t-test. Rumus Short method digunakan dalam penelitian ini karena lebih efisien penggunaannya. (Hari, 2017). Kriteria pengujiannya, tolak Ho jika diperoleh nilai thitung $>$ ttabel pada taraf signifikansi $5 \%$ dengan $\mathrm{dk}=\mathrm{n}-1$. Pengujian menggunakan uji $\mathrm{t}$ ini dapat dilanjutkan apabila secara signifikan berdistribusi normal, yang diuji menggunakan Kolmogorov Smirnov jika diperoleh nilai probabilitas $>0,05$. Apabila tidak berdistribusi normal, sebagai pengganti uji t berupa uji Wilcoxon pada statistik non parametric

\section{Hasil dan Pembahasan}

Hasil penelitian ini merupakan hasil pengukuran kapasitas vital paru usia lanjut sebelum dan sesudah mengikuti latihan Senam Sehat Indonesia di Universitas Majalengka. Pengukuran dilakukan pada 20 orang yang berusia lanjut (berusia diatas atau sama dengan 55 tahun).

Tabel 1. Distribusi Frekuensi Umur Responden

\begin{tabular}{cccc}
\hline No & Umur & $\mathrm{f}$ & $\%$ \\
\hline 1 & $55-60$ & 8 & 36.67 \\
\hline 2 & $61-65$ & 5 & 26.67 \\
\hline 3 & $66-70$ & 5 & 26.67 \\
\hline 4 & $71-75$ & 2 & 10.00 \\
\hline & Jumlah & 20 & 100.00 \\
\hline
\end{tabular}


Berdasarkan data yang diperoleh terdapat 36,67\% responden berumur antara 55-60 tahun, 26,67\% antara 61-65 tahun, 26,67\% antara 66-70 tahun dan 10\% antara 71-75 tahun.

1. Data Kapasitas Vital Paru Sebelum Mengikuti Latihan Senam Sehat Indonesia

Rata-rata kapasitas vital paru hasil pengukuran sebelum mengikuti latihan Senam Sehat Indonesia dapat dilihat pada tabel 2 .

Tabel 2. Rata-rata Kapasitas Vital Paru Sebelum mengikuti latihan Senam Sehat Indonesia

\begin{tabular}{lc}
\hline & $\begin{array}{c}\text { Kapasitas vital paru sebelum mengikuti } \\
\text { senam sehat Indonesia }\end{array}$ \\
\hline Minimum & 500.00 \\
Maximum & 1500.00 \\
Mean & 946.0000 \\
Std. Deviation & 259.2376 \\
Variance & 67204.138 \\
\hline
\end{tabular}

Rata-rata kapasitas vital paru sebelum mengikuti latihan Senam Sehat Indonesia mencapai 946 $\mathrm{ml}$ dengan standar deviasi 259,2376. Hal ini menunjukkan bahwa kapasitas vital paru sebelum mengikuti latihan Senam Sehat Indonesia bervariasi dengan kapasitas vital paru terendah $500 \mathrm{ml}$ dan tertinggi $1500 \mathrm{ml}$.

Kegiatan latihan Senam Sehat Indonesia di Universitas Majalengka dilaksanakan sejak Bulan Juni-Agustus 2020. Setiap minggunya dilaksanakan 3 kali latihan, dimana setiap latihan melalui tiga proses yaitu pemanasan 15 menit, inti 30 menit dan pendinginan dalam waktu 17 menit. Pelatih terdiri dari satu orang. Rata-rata kapasitas vital paru hasil pengukuran setelah mengikuti latihan Senam Sehat Indonesia dapat dilihat pada tabel 3.

Tabel 3. Rata-rata Kapasitas Vital Paru Setelah Mengikuti Latihan Senam Sehat Indonesia

\begin{tabular}{lc}
\hline & $\begin{array}{c}\text { Kapasitas vital paru setelah mengikuti } \\
\text { senam sehat Indonesia }\end{array}$ \\
\hline Minimum & 620.00 \\
Maximum & 1600.00 \\
Mean & 1013.3333 \\
Std. Deviation & 284.1240 \\
Variance & 80726.437 \\
\hline
\end{tabular}

Rata-rata kapasitas vital paru setelah mengikuti latihan Senam Sehat Indonesia mencapai 1013,33 $\mathrm{ml}$ dengan standar deviasi 284,1240. Terlihat dari tabel dan grafik bahwa kapasitas vital paru-paru setelah mengikuti latihan Senam Sehat Indonesia juga bervariasi dengan kapasitas vital paru terendah $620 \mathrm{ml}$ dan tertinggi $1600 \mathrm{ml}$.

Uji normalitas data digunakan untuk mengetahui data yang diperoleh terdistribusi normal atau tidak. Dalam pengujiannya dapat dilihat dari Kolmogorov Smirnov, apabila diperoleh nilai Lo dengan signifikansi $<0,01$ maka dapat disimpulkan bahwa data tidak terdistribusi normal. Hasil uji Kolmogorov Smirnov dapat dilihat dari output SPSS pada tabel berikut.

Tabel 4. Uji Normalitas Data

\begin{tabular}{|c|c|c|c|c|c|c|}
\hline & \multicolumn{3}{|c|}{ Kolmogorov-smirnova } & \multicolumn{3}{|c|}{ Shapiro-Wilk } \\
\hline & Statistic & $\mathrm{df}$ & Sig. & Statistic & $\mathrm{df}$ & Sig. \\
\hline $\begin{array}{c}\text { Kapasitas vital paru sebelum mengikuti } \\
\text { senam sehat Indonesia }\end{array}$ & .147 & 20 & .098 & .965 & 20 & .470 \\
\hline $\begin{array}{c}\text { Kapasitas vital paru setelah mengikuti } \\
\text { senam sehat Indonesia }\end{array}$ & 162 & 20 & .042 & .923 & 20 & .043 \\
\hline
\end{tabular}


Berdasarkan tabel diatas diperoleh nilai signfikansi untuk kapasitas vital paru sebelum mengikuti latihan Senam Sehat Indonesia sebesar 0,098 dan setelah mengikuti latihan Senam Sehat Indonesia sebesar 0,042. Kedua nilai signifikansi pengujian tersebut $>0,01$ maka dapat disimpulkan bahwa data terdistribusi normal. Sehingga untuk pengujian hipotesis selanjutnya digunakan statistik parametrik yaitu uji t.

Untuk mengetahui peningkatan kapasitas vital paru setelah mengikuti latihan Senam Sehat Indonesia dapat dilihat dari uji t seperti pada tabel berikut.

Tabel 5. Uji Peningkatan Kapasitas Vital Paru Setelah Mengikuti Latihan Senam Sehat Indonesia

\begin{tabular}{cccccc}
\hline Kapasitas Vital Paru & Rata-rata & Peningkatan & thitung & ttabel & Keterangan \\
\hline Sebelum Latihan & 946.00 & \multirow{2}{*}{$7.12 \%$} & \multirow{2}{*}{3.68} & \multirow{2}{*}{2.46} & \multirow{2}{*}{ Ho ditolak } \\
\hline Sesudah Latiham & 1013.33 & & & & \\
\hline
\end{tabular}

Keterangan:

Ho: $\mu 1>\mu 2$ (Tidak meningkat) Ho: $\mu 1<\mu 2$ (terjadi peningkatan)

Berdasarkan hasil uji t diatas diperoleh nilai thitung sebesar 3,68 > ttabel $(2,46)$ pada taraf signfikansi 0,01 yang berarti Ho dengan pernyataan tidak ada peningkatan kapasitas vital paru ditolak, sedangkan $\mathrm{Ha}$ dengan pernyataan ada peningkatan kapasitas vital paru usia lanjut diterima dengan peningkatan sebesar $7,12 \%$.

Berdasarkan hasil penelitian menunjukkan bahwa ada peningkatan yang signifikan kapasitas vital paru pada usia lanjut setelah mengikuti latihan Senam Sehat Indonesia di Universitas Majalengka. Terjadinya peningkatan kapasitas vital paru usia lanjut disebabkan karena respons tubuh secara faal yaitu menebalnya otot-otot diafragma yang mengakibatkan proses respirasi dapat dilakukan secara maksimal. Senam Sehat Indonesia menggunakan metode latihan pernafasan diafragma. Menurut Nakamura dalam Baranas SSI (1989), pernafasan dengan diafragma menyebabkan volume O2 yang masuk ke paru-paru lebih banyak sehingga jantung dapat memompa darah lebih banyak. Latihan pernafasan inilah yang memberikan kontribusi yang nyata terhadap peningkatan kapasitas vital paru bagi usia lanjut di Universitas Majalengka. Dalam Senam Sehat Indonesia, terdapat unsur-unsur latihan yaitu latihan peregangan, latihan meningkatkan kelenturan sendi, latihan balance dan koordinasi yang bermanfaat untuk menguatkan fungsi sistem lokomotor yaitu sendi tulang, otot dan saraf tepi. Dalam komponen kesegaran fisik yang lain, SSI membantu meningkatkan ketahanan jantung dan paru-paru, namun tidak meningkatkan daya ledak otot, kecepatan dan ketangkasan. (Baranas SSI, 1989).

\section{Kesimpulan}

Berdasarkan hasil penelitian dapat diambil kesimpulan bahwa Senam Sehat Indonesia dapat mempengaruhi peningkatan kapasitas vital paru usia lanjut. Latihan Senam Sehat Indonesia memberikan kontribusi yang signifikan terhadap peningkatan kapasitas vital paru usia lanjut, yaitu sebesar 7,12\%. Berdasarkan kesimpulan maka dapat disarankan usia lanjut di Universitas Majalengka untuk lebih termotivasi dalam melakukan kegiatan Senam Sehat Indonesia sebagai salah satu bentuk latihan pembinaan kondisi fisik yang prima dalam menjaga tingkat kesegaran jasmani..

\section{Daftar Pustaka}

Baranas. (1989). Senam Sehat Indonesia. Yogyakarta.

Beltasar \& Novi. (2010). Pengarub Latihan Senam Tai Chi dan Wai Tan Kung terbadap Daya Tahan Jantung Paru dan Komposisi Tubuh (Persentase Lemak Tubub Pada Lanjut Usia). Bandung: UNPAD

BKKBN. (1996). Materi Penyuluban Bina Keluarga Lansia

Cheung, Siu Yin. (2020). Gymnastics for all in Hong Kong. International Journal of Physical Education, Sports and Health; 7(4): 11-15) 
Claudia Voelcker-Rehage. (2008). Motor-skill learning in older adults A review of studies on age-related differences. Eouropean Review of Aging and Physical Activity 5(1):5-16

Darmojo. dan Martono. (2004). Geriatri. Jakarta: Balai Penerbit FKUI

Emma S. W. (2002). Tetap Bugar Di Usia Lanjut. Jakarta: Trubus Agriwidya

Gibson, J. (2002). Fisiologi Untuk Kedokteran. Jakarta: PT. Gramedia Pustaka Utama

Hari, P. (2017). Statistik Dasar. Sebuah Panduan untuk Peneliti Pemula. Lembaga Pendidikan dan Pelatihan. International English Institute of Indonesia. Mojokerto, Jawa Timur, Indonesia.

Indrayogi, I. (2020). Korelasi Antara Tingkat Kesegaran Jasmani (Physical Fitness) Dan Kesehatan Mental (Mental Hygiene) Dengan Prestasi Belajar Pendidikan Jasmani Siswa Sekolah Dasar. Jurnal Respecs, 2(1).

Nibras N. (2019). Hanya 13,2 Persen Lansia Di Indonesia Yang Sehat. https://sains.kompas.com/read/2019/07/05/120500723/

Oktariyana, Asmawi, \& Zamzami. (2020). Enhancement of Students' Fitness Using Rhythmic Gymnastics (Batara Gymnastics). Journal of Physical Education, Sport, Health and Recreations 9 (1) (2020) 23 - 27. http://journal.unnes.ac.id/sju/index.php/peshr

Oktia W. K. H. (1999). Praktikum dan Keteramplan Pendidikan Kesehatan. Semarang.

Oluwasegun, A. I. (2018). Physical Activity, Nutrition and Health: An antidote to overall wellbeing. International Journal of Physical Education, Sports and Health 2018; 5(5): 01-05

Pearce, E. C. (1993). Anatomi dan Fisiologi Untuk Paramedis. Jakarta:PT.Gramedia Pustaka Utama

Poerwadarminta, W.J.S. (1984). Kamus Besar Bahasa Indonesia. Jakarta: Balai Pustaka 